\title{
Adults with corrected oesophageal atresia: is oesophageal function associated with complaints and/or quality of life?
}

\author{
J. A. Deurloo • E. C. Klinkenberg · S. Ekkelkamp • \\ H. A. Heij · D. C. Aronson
}

Accepted: 27 February 2008/Published online: 20 March 2008

(C) The Author(s) 2008

\begin{abstract}
The aim of this study was to evaluate oesophageal function after correction of oesophageal atresia in adults, and to investigate the association between complaints, oesophageal function and quality of life (QoL). Twenty-five adults were included who participated in previous follow-up studies, during which complaints of dysphagia and gastro-oesophageal reflux (GOR), results of upper gastrointestinal endoscopy, oesophageal biopsies and QoL had been collected. Manometry was performed in 20 patients, $24 \mathrm{~h} \mathrm{pH}$-measurements were performed in 21 patients. $\mathrm{pH}$-values (sample time $5 \mathrm{~s}$ ) were calculated using criteria of Johnson and DeMeester. Associations were tested with ANOVA and $\chi^{2}$-tests. Ten patients (48\%) reported complaints of dysphagia, seven (33\%) of GOR. The amplitude of oesophageal contractions was low $(<15 \mathrm{mmHg})$ in four patients $(20 \%)$. pH-measurements showed pathological reflux in three patients (14\%). Patients reporting dysphagia more often had disturbed motility $(P=0.011)$, and lower scores on the domains "general health perceptions" (SF-36) $(P=0.026)$, "standardised physical component" (SF-36) $(P=0.013)$, and "physical well-being" (GIQLI) (0.047). No other associations were found. This study shows a high percentage of oesophageal motility disturbances and a moderate percentage of GOR after correction of oesophageal atresia. Patients reporting
\end{abstract}

J. A. Deurloo · S. Ekkelkamp · H. A. Heij · D. C. Aronson ( $\square)$ Pediatric Surgical Center of Amsterdam,

Emma Children's Hospital AMC

and Vrije Universiteit Medical Center,

P. O. Box 22660, 1100 DD Amsterdam, The Netherlands

e-mail: d.c.aronson@amc.uva.nl

E. C. Klinkenberg

Department of Gastroenterology, Vrije Universiteit Medical

Center, P. O. Box 7057, 1007 MB Amsterdam, The Netherlands dysphagia, whom more often had disturbed motility, seemed to be affected by these symptoms in their QoL.

Keywords Oesophageal atresia - Long-term follow-up · Manometry · pH-measurements · Quality of life

\section{Introduction}

At present, the survival rate of patients with oesophageal atresia (OA) is approximately 95\% [1, 2]. With the decreased mortality, the interest in morbidity, especially the long-term results after correction of $\mathrm{OA}$, has increased over the years.

Several long-term follow-up studies have shown that long lasting gastro-oesophageal reflux (GOR) is a frequent problem after correction of OA, although intestinal metaplasia, as its theoretical consequence, is rare [3-6]. In these studies, GOR has been either diagnosed by upper gastrointestinal (GI) endoscopy with biopsies, by $24 \mathrm{~h} \mathrm{pH}-$ measurements, or by both, showing varying degrees of GOR. Besides pH-measurements, oesophageal manometry has been performed in several studies, showing oesophageal motility disturbances in most patients [7-10]. The true impact of this finding on individual daily life is not clear.

In our centre, we have performed several long-term follow-up studies in a relatively large group of patients after correction of OA [5, 6]. Patients underwent upper GI endoscopy with biopsies and quality of life (QoL) measurements [11].

The first aim of this study was to evaluate the presence of GOR and oesophageal motility problems in a group of our adult patients treated for OA.

The second aim was to investigate if there was an association between complaints, oesophageal function, and 
QoL-measurements. This association has not been investigated before. Because of the influence of complaints of dysphagia and GOR on daily life, we hypothesised that patients with complaints have a poorer QoL than patients without complaints.

\section{Patients and methods}

Twenty-five patients over 18 years of age who participated in previous follow-up studies after correction of OA [5, 6, 11], and gave informed consent to participate, were included in this study. In these previous studies, data regarding the results of upper GI endoscopy, biopsies of the distal oesophagus, and QoL had been collected. From the QoL study, we used the results of the Medical Outcome Study 36-Item Short-Form Health Survey (SF-36) and of the gastro-intestinal quality of life index (GIQLI) [12, 13]. After approval of the study protocol by the Medical Ethical Committee, all patients received a written invitation to participate in the study.

All patients who gave their informed consent, underwent manometry and pH-measurements and were asked if they experienced difficulties swallowing solid foods (dysphagia) or experienced heartburn or retrosternal pain (GOR-related complaints). Oesophageal manometry was performed using the UPS-2020 measurement stationary system (MMS, Enschede, The Netherlands) with software version 7.

The pressure was measured with the Unisensor Microtip catheter type 8304-00-9980-D with three pressure transducers on a $5 \mathrm{~cm}$ distance from each other. The lower oesophageal sphincter basal or resting pressure (LOSP) and relaxation after swallowing, the motility in the oesophageal body after at least six wet swallows of $5 \mathrm{ml}$ water, and the upper oesophageal sphincter pressure (UOSP) and relaxation were calculated. The amplitude of oesophageal body contractions was categorized as "low" ( $<15 \mathrm{~mm} \mathrm{Hg})$, "moderate" (15-35 mm Hg), or "normal" (>35 mm Hg). The encountered oesophageal motility disorders were classified according to the guidelines proposed by Spechler et al. [14]. Based on the basal LOSP, LOS relaxation, peristaltic wave progression, and distal wave amplitude, oesophageal motility disorders were classified into four categories: (1) "inadequate LOS relaxation", (2) "uncoordinated contraction", (3) "hypercontraction", and (4) "hypocontraction" or "ineffective oesophageal motility".

$\mathrm{pH}$-measurements were performed using the Comfortec dual channel $\mathrm{pH}$ probe (Sandhill Scientific), which was positioned with the $\mathrm{pH}$ measurement points 5 and $20 \mathrm{~cm}$ above the manometrically established upper border of the LOS. The position of the probe was checked by X-ray. Ambulatory $\mathrm{pH}$ measurement was performed during $24 \mathrm{~h}$ using the GORD pH-recorder (Sandhill Scientific) with a sample time of every $5 \mathrm{~s}$. The $\mathrm{pH}$ values were calculated using the criteria of Johnson and DeMeester [15].

The data were entered into a database and analysis was performed using SPSS (Statistical Package of the Social Sciences) 10.0.1 for Windows. We tested for association between functional results and QoL by applying ANOVA and $\chi^{2}$-tests or Fisher's exact tests.

\section{Definitions}

Before testing for association, the results of functional tests were dichotomized. If upper GI endoscopy showed a normal oesophagus or grade I oesophagitis (according to the modified system of Savary-Miller) [16], this was scored as "normal". Grade II oesophagitis or worse was scored as "abnormal". If the biopsies of the distal oesophagus showed normal oesophageal epithelium or mild reflux oesophagitis (according to Ismael-Beigi) [17], this was scored as "normal". Moderate oesophagitis or worse was scored as "abnormal". As all patients were diagnosed as having "ineffective oesophageal motility", this variable could not be used. Instead, we used the amplitude of oesophageal body contractions as a measure of outcome of manometry, because decreased amplitude implies a defective peristaltic function of the oesophagus. The results were dichotomized as "normal" or "abnormal" (moderate or low amplitude). The results of $\mathrm{pH}$-measurements were also dichotomized as "normal" or "abnormal" (minor or pathological reflux).

\section{Results}

\section{Patient characteristics}

Patient characteristics are described in Table 1. All patients had undergone a primary end-to-end anastomosis for Gross' type C OA. Two patients were using proton-pump inhibitors, they stopped taking their medication two days before the start of the study.

Unfortunately, it was impossible to perform manometry and $\mathrm{pH}$-measurements in four patients. In one patient it was impossible to introduce the catheter through the nose due to resistance of the patient, who decided to withdraw from the study. In three out of four patients it was impossible to introduce the catheter due to oesophageal stricture. All of these three patients had been treated for anastomotic stricture in childhood, one patient had undergone antireflux surgery in childhood. Two of these three patients had complaints of dysphagia at the time of the study. The stricture of these three patients was treated with dilatation. Since dilatations may influence the results of manometry and $\mathrm{pH}$-measurements, no measurements were performed 
Table 1 Patient characteristics of 25 patients participating in the study

\begin{tabular}{ll}
\hline & Mean (range) or $\mathrm{n}(\%)$ \\
\hline Age (years) & $28.5(18-42)$ \\
Gender & \\
Male & $16(64 \%)$ \\
Female & $9(36 \%)$ \\
Concomitant congenital anomalies & \\
None & $17(68 \%)$ \\
Present & $8(32 \%)$ \\
Anorectal malformations & $3(12 \%)$ \\
Cardiac malformations & $4(16 \%)$ \\
Vertebral malformations & $1(4 \%)$ \\
Limb malformations & $2(8 \%)$ \\
Other malformations & $2(8 \%)$ \\
Anti-reflux procedure in past & \\
No & $23(92 \%)$ \\
Yes & $2(8 \%)$ \\
Anastomotic stenosis in past & \\
No & $18(72 \%)$ \\
Yes & $7(28 \%)$ \\
Current educational status & \\
Primary school & $1(4 \%)$ \\
Basic high school & $9(36 \%)$ \\
Advanced high school & $7(28 \%)$ \\
University & $5(20 \%)$ \\
Unknown & $3(12 \%)$ \\
\hline &
\end{tabular}

in these patients. Due to a technical failure, the data of the manometry of one patient could not be retrieved.

Dysphagia was reported by $10 / 21$ patients (48\%), GORrelated symptoms were reported by $7 / 21$ patients $(33 \%)$.

\section{Manometry}

The data of 20 patients could be analyzed. The upper oesophageal sphincter (UOS) responded normally to swallowing in all patients. Mean UOS pressure was $30.8 \pm 15.5 \mathrm{~mm} \mathrm{Hg}$.

Oesophageal contractions were observed in all patients. One or more propulsive contractions were observed in 14/ 20 patients. All patients showed one or more non-transmitted contractions. Retrograde contractions were observed in $7 / 20$ patients. Mean minimum oesophageal body amplitude pressure was $20.7 \pm 13.4 \mathrm{~mm} \mathrm{Hg}$. Mean maximum oesophageal body amplitude pressure was $32.0 \pm 15.5 \mathrm{~mm} \mathrm{Hg}$. The amplitude of oesophageal body contractions was low $(<15 \mathrm{~mm} \mathrm{Hg})$ in 4 patients $(20 \%)$, moderate $(15-35 \mathrm{~mm} \mathrm{Hg})$ in $10(50 \%)$ and normal $(>35 \mathrm{~mm} \mathrm{Hg})$ in $6(30 \%)$.
In all patients, the LOS showed complete relaxation upon swallowing. Mean LOSP was $13.1 \pm 7.2 \mathrm{~mm} \mathrm{Hg}$.

According to the guidelines of Spechler et al., all patients were classified as having "ineffective oesophageal motility" [16]. The LOS pressure was normal and LOS relaxation was complete in all patients. Wave progression varied from normal to absent progression, and the distal wave amplitude was low in $\geq 30 \%$ of wet swallows (data not shown).

$\mathrm{pH}$-measurements

The data of 21 patients could be analyzed. The results are described in Table 2. $\mathrm{pH}$-measurements showed a normal pattern in 17 patients $(81 \%)$, minor reflux in $1(5 \%)$, and pathological reflux in $3(14 \%)$. In both of the patients who were taking proton-pump inhibitors, $\mathrm{pH}$-measurements showed pathological reflux.

Associations

The association between symptoms and results of endoscopy, oesophageal biopsies, manometry, $\mathrm{pH}$-measurements and QoL is shown in Table 3. Patients reporting dysphagia, more often had disturbed motility $(P=0.011)$. These patients also had significantly lower scores on the domains "general health perceptions" $(P=0.026)$, and "standardised physical component" $(P=0.013)$ of the SF-36; and on the domain "physical well-being" $(P=0.047)$ of the GIQLI.

No association was found between complaints of GOR and quality of life; nor between the results of endoscopy and the results of $\mathrm{pH}$-measurement and/or manometry; nor between the results of oesophageal biopsies and the results of pH-measurement and/or manometry (data not shown). Problems with the initial surgical repair in childhood (i.e. anastomotic leak or stricture needing dilatation) did not influence the findings in the current study.

\section{Discussion}

The results of the present study confirm that oesophageal motility disturbances are frequently present after correction of OA. Low or moderate amplitude of oesophageal body

Table 2 Results of $24 \mathrm{~h} \mathrm{pH}$-measurements in 21 patients

\begin{tabular}{lll}
\hline & $\begin{array}{l}\text { Proximal mean } \\
\% \pm \mathrm{SD}\end{array}$ & $\begin{array}{l}\text { Distal mean } \\
\% \pm \mathrm{SD}\end{array}$ \\
\hline Total time $\mathrm{pH}<4$ & $0.2 \pm 0.4$ & $1.5 \pm 2.2$ \\
Upright time $\mathrm{pH}<4$ & $0.2 \pm 0.6$ & $2.2 \pm 3.3$ \\
Supine time $\mathrm{pH}<4$ & $0.0 \pm 0.3$ & $0.4 \pm 1.0$
\end{tabular}

$S D$ standard deviation 
Table 3 Association between symptoms and results of endoscopy, oesophageal biopsies, manometry, $\mathrm{pH}$ measurements, and quality of life

Data are shown as $n$, or mean (standard deviation)

GOR gastro-oesophageal reflux, SF-36 Medical Outcome Study 36-Item Short Form Health Survey, PCS physical component summary, $M C S$ mental component summary, GIQLI gastro-intestinal quality of life index

${ }^{*} P=0.011,{ }^{* *} P=0.026$,

${ }^{* * * *} P=0.013,{ }^{* * * *} P=0.047$

\begin{tabular}{|c|c|c|c|c|}
\hline & \multicolumn{4}{|l|}{ Complaints } \\
\hline & \multicolumn{2}{|l|}{ Dysphagia } & \multicolumn{2}{|l|}{ GOR } \\
\hline & Yes & No & Yes & No \\
\hline \multicolumn{5}{|l|}{ Endoscopy } \\
\hline Normal & 9 & 9 & 6 & 12 \\
\hline Abnormal & 1 & 2 & 1 & 2 \\
\hline \multicolumn{5}{|l|}{ Oesophageal biopsies } \\
\hline Normal & 6 & 5 & 4 & 7 \\
\hline Abnormal & 3 & 5 & 2 & 6 \\
\hline \multicolumn{5}{|l|}{ Manometry } \\
\hline Normal & $0^{*}$ & $6^{*}$ & 1 & 5 \\
\hline Abnormal & $10^{*}$ & $4^{*}$ & 6 & 8 \\
\hline \multicolumn{5}{|l|}{$\mathrm{pH}$-measurements } \\
\hline Normal & 10 & 7 & 5 & 12 \\
\hline Abnormal & 0 & 4 & 2 & 2 \\
\hline \multicolumn{5}{|l|}{ SF-36 scales } \\
\hline Physical functioning & $86.5(19.2)$ & $94.1(8.3)$ & $96.7(5.2)$ & $88.1(16.4)$ \\
\hline Physical role-functioning & $77.8(38.4)$ & $100.0(0.0)$ & $83.3(40.8)$ & $92.9(20.6)$ \\
\hline Emotional role-functioning & $77.8(44.1)$ & $96.7(10.1)$ & $83.3(40.8)$ & $90.5(27.5)$ \\
\hline Bodily pain & $78.2(26.3)$ & $92.5(13.9)$ & $85.5(24.5)$ & $86.3(20.5)$ \\
\hline General health & $63.6(23.6)^{* *}$ & $84.6(15.1)^{* *}$ & 86.7 (14.8) & $70.2(22.7)$ \\
\hline Vitality & $50.0(15.4)$ & $52.3(12.9)$ & $58.3(13.3)$ & $48.2(13.2)$ \\
\hline Social functioning & $88.9(22.0)$ & $93.2(18.8)$ & $97.9(5.1)$ & $88.4(23.2)$ \\
\hline Mental health & $82.7(15.7$ & $81.5(16.7)$ & $87.3(12.5)$ & $79.7(17.0)$ \\
\hline \multicolumn{5}{|c|}{ SF-36 component summary scales } \\
\hline PCS & $49.5(7.4)^{* * *}$ & $56.4(3.4)^{* * *}$ & $55.6(4.9)$ & $52.3(6.9)$ \\
\hline MCS & $49.0(10.9)$ & $49.5(7.4)$ & $50.3(7.9)$ & $48.8(9.5)$ \\
\hline \multicolumn{5}{|l|}{ GIQLI scales } \\
\hline Physical well-being & $21.2(3.1)^{* * * *}$ & $24.5(3.7)^{* * * *}$ & $23.3(3.8)$ & $22.9(3.9)$ \\
\hline GI symptoms & $64.1(8.5)$ & $68.6(7.8)$ & $68.0(6.5)$ & $66.0(9.0)$ \\
\hline Social well-being & $12.0(1.7)$ & $12.2(0.4)$ & $12.0(0.6)$ & $12.1(1.3)$ \\
\hline Emotional well-being & $15.1(1.5)$ & $15.9(0.5)$ & $15.5(1.0)$ & $15.6(1.2)$ \\
\hline Total score & $112.4(13.3)$ & $121.3(9.6)$ & $118.8(10.3)$ & $116.6(12.9)$ \\
\hline
\end{tabular}

contractions were found in $14 / 20$ patients (70\%), all patients showed one or more non-transmitted contractions, and retrograde contractions were observed in $7 / 20$ patients (35\%). All patients met the manometric features of "ineffective oesophageal motility", as described by Spechler et al. [14]. The manometric findings in the present study are comparable to those described in other studies [7-10].

Based on pH-measurements, the prevalence of GOR in the current patient group is lower than expected. $\mathrm{pH}$ measurements showed minor or pathological reflux in 4/20 patients $(20 \%)$. None of these patients had undergone antireflux surgery in the past. In other studies, the prevalence of GOR based on $\mathrm{pH}$-measurements varies from 17 to $54 \%$ [7-9]. Unfortunately, the criteria used for diagnosing GOR and the age of the patient groups studied also vary between studies.
The question is, what the influence is of the disturbed oesophageal motility and GOR found in previous studies on the daily life of adults with corrected OA. This is the first study in which complaints and QoL after correction of OA have been combined with long-term studies of oesophageal function: endoscopy, oesophageal biopsies, manometry and $\mathrm{pH}$-measurements. Patients reporting dysphagia more often had disturbed motility, and showed significantly lower scores on the domains "general health perceptions" and "standardised physical component" of the SF-36, and on the domain "physical well-being" of the GIQLI. However, GOR-related complaints were not associated with disturbed oesophageal function, and did not influence QoL. It is important to consider that this group of patients has grown up with these symptoms, and may probably have gotten used to it. The fact that complaints of 
dysphagia affect the QoL and GOR-related complaints do not affect QoL may be explained by the influence of these complaints on daily activities such as eating.

Motility problems after correction of OA were first reported by Haight [18] in 1957. The main cause of the abnormal oesophageal motility after correction of OA is not clear. Some studies propose a congenital nervous abnormality as the cause of motility disturbances. In the foetal rat model for OA, abnormalities were found in the course and branching pattern of the vagal nerves [19]. However, an acquired cause is also suggested, i.e. surgical damage to vagal fibres that innervate the oesophagus [20]. Abnormal oesophageal motility can cause symptoms of dysphagia. It can also worsen the effects of GOR, since malfunction of the peristaltic pump will result in a delayed clearance with a longer period of stasis of refluxed material in the oesophagus.

In conclusion, this study shows a high percentage of oesophageal motility disturbances and a moderate percentage of GOR after correction of OA. Only patients reporting dysphagia, who more often had disturbed motility, appeared to be affected by these symptoms in their QoL.

Open Access This article is distributed under the terms of the Creative Commons Attribution Noncommercial License which permits any noncommercial use, distribution, and reproduction in any medium, provided the original author(s) and source are credited.

\section{References}

1. Deurloo JA, Ekkelkamp S, Schoorl M et al (2001) Esophageal atresia: historical evolution of management and results in 371 patients. Ann Thorac Surg 73:268-272

2. Rokitansky AM, Kolankaya VA, Seidl S et al (1993) Recent evaluation of prognostic risk factors in esophageal atresia-a multicenter review of 223 cases. Eur J Pediatr Surg 3:196-201

3. Lindahl H, Rintala R, Sariola H (1993) Chronic esophagitis and gastric metaplasia are frequent late complications of esophageal atresia. J Pediatr Surg 28:1178-1180

4. Somppi E, Tammela O, Ruuska T et al (1998) Outcome of patients operated on for esophageal atresia: 30 years' experience. J Pediatr Surg 33:1341-1346
5. Deurloo JA, Ekkelkamp S, Bartelsman JFWM et al (2003) Gastroesophageal reflux: prevalence in adults more than 28 years after correction of esophageal atresia. Ann Surg 238:686-689

6. Deurloo JA, Ekkelkamp S, Taminiau JAJM et al (2005) Esophagitis and Barrett's esophagus after correction of esophageal atresia. J Pediatr Surg 40:1227-1231

7. Orringer MB, Kirsh MM, Sloan H (1977) Long-term esophageal function following repair of esophageal atresia. Ann Surg 186:436-443

8. Tomaselli V, Volpi ML, Dell'Agnola CA et al (2003) Long-term evaluation of esophageal function in patients treated at birth for esophageal atresia. Pediatr Surg Int 19:40-43

9. Tovar JA, Diez-Pardo JA, Murcia J et al (1995) Ambulatory 24hour manometric and $\mathrm{pH}$ metric evidence of permanent impairment of clearance capacity in patients with esophageal atresia. J Pediatr Surg 30:1224-1231

10. Dutta HK, Grover VP, Dwivedi SN et al (2001) Manometric evaluation of postoperative patients of esophageal atresia and tracheo-esophageal fistula. Eur J Pediatr Surg 11:371-376

11. Deurloo JA, Ekkelkamp S, Hartman EE et al (2005) Quality of life in adult survivors of correction of oesophageal atresia. Arch Surg 140:976-980

12. Ware JE Jr, Sherbourne CD (1992) The MOS 36-item short-form health survey (SF-36). I. Conceptual framework and item selection. Med Care 30:473-483

13. Eypasch E, Williams JI, Wood-Dauphinee S et al (1985) Gastrointestinal Quality of Life Index: development, validation and application of a new instrument. Br J Surg 82:216-222

14. Spechler SJ, Castell DO (2001) Classification of oesophageal motility abnormalities. Gut 49:145-151

15. Johnson LF, DeMeester TR (1974) Twenty-four-hour pH monitoring of the distal esophagus. A quantitative measure of gastroesophageal reflux. Am J Gastroenterol 62:325-332

16. Ollyo JB, Lang F, Fontollet Ch et al (1990) Savary's new endoscopic grading of reflux oesophagitis: a simple, reproducible, logical, complete and useful classification. Gastroenterology 98:A100

17. Ismail-Beigi F, Pope CE (1974) Distribution of the histological changes of gastroesophageal reflux in the distal esophagus of man. Gastroenterology 66:1109-1113

18. Haight C (1957) Some observations on esophageal atresias and tracheo-esophageal fistulas of congenital origin. J Thorac Surg 34:141-147

19. Qi BQ, Merei J, Farmer P et al (1997) The vagus and recurrent laryngeal nerves in the rodent experimental model of esophageal atresia. J Pediatr Surg 32:1580-1586

20. Shono T, Suita S (1997) Motility studies of the esophagus in a case of esophageal atresia before primary anastomosis and in experimental models. Eur J Pediatr Surg 7:138-142 